Recibido: 18-julio-2013

Aceptado: 18-agosto-2013

\title{
UNA VISIÓN CIENTÍFICA AL SISTEMA FILOSÓFICO DE FRIEDRICH NIETZSCHE
}

Wilson P. Álvarez-Samaniego

Núcleo de Investigadores Científicos

Facultad de Ingeniería, Ciencias Físicas y Matemática Universidad Central del Ecuador

Borys Álvarez-Samaniego

Núcleo de Investigadores Científicos Facultad de Ingeniería, Ciencias Físicas y Matemática Universidad Central del Ecuador

Douglas Moya-Álvarez

Núcleo de Investigadores Científicos Facultad de Ingeniería, Ciencias Físicas y Matemática Universidad Central del Ecuador 


\section{RESUMEN}

Se ha considerado a Nietzsche como uno de los pensadores más influyentes en la filosofía de occidente de fines del siglo XIX y hasta la actualidad. Sus propuestas han sido críticas a los valores éticos, estéticos y científicos del pensamiento Judeo-Cristiano de occidente. Este trabajo considera algunos de los efectos científicos de su discurso, tomando en cuenta su marco histórico y su biografía. Se señalan las propuestas centrales de su filosofía: la muerte de Dios, el advenimiento del superhombre, la voluntad de poder y el eterno retorno de lo mismo. Dichas propuestas son analizadas y confrontadas con los actuales conocimientos científicos. Esta confrontación es considerada en vista de algunas de sus consecuencias epistemológicas: la negación de la racionalidad humana y la negación de la existencia de las leyes naturales. Así, Nietzsche abre el renacimiento del pensamiento mágico y la negación de la ciencia. La columna vertebral de sus propuestas filosóficas es la del individualismo, así resultaría posible la existencia humana en el contexto de la más absoluta soledad. Este último punto está en contradicción con los resultados presentados por los autores en [1], por los cuales la existencia individual y las características son el resultado y la manifestación singular de la totalidad del Universo.

Palabras clave: individualismo, nihilismo, constante de Planck, campo de acción de fondo.

\section{ABSTRACT}

Nietzsche is considered one of the most influential thinkers of western philosophy from the end of the 19th century to the present day. His proposals have criticized the ethical, aesthetic and scientific values of the Judeo-Christian thoughts in the West. This paper considers some of the scientific effects of his work taking into account his biography and his historical context. The main proposals of his philosophy are captured as: the death of God, the advent of the superman, the will of power and the eternal recurrence of the same. These proposals are analyzed and confronted with current scientific knowledge. This confrontation is considered in the light of some of its epistemological consequences: the negation of human rationality and the negation of the existence of natural laws. Thus, Nietzsche opens the Renaissance of magical thinking and the denial of science. The backbone of his philosophical proposals is individualism, thus the human existence in the context of the most absolute solitude would be possible. This last point is in contradiction with the results presented by the authors in [1], where the individual existence and characteristics are the result and the singular manifestation of the whole universe.

Keywords: individualism, nihilism, Planck's constant, background action field. 


\section{Nietzsche en su Marco Histórico}

El filósofo Friedrich Nietzsche (15/10/1844-25/08/1900) al enfrentarse en su juventud al conjunto de cambios por los que estaba pasando Europa en el contexto del desarrollo del capitalismo durante la revolución industrial, influenciado por el filósofo alemán Arthur Schopenhauer y la lectura de la Historia del materialismo de Friedrich Albert Lange, llegó a tener una concepción trágica de la vida, de la cual solo se podía salir a través de la experiencia artística donde se encontraba verdaderamente la redención. Así, se convirtió en admirador del compositor Richard Wagner, con el cual luego haría amistad. En ese periodo escribe $E$ I origen de la tragedia en el espíritu de la música. Sin embargo, cuando Wagner comienza a tener inclinaciones nacionalistas dentro de la tendencia pangermánica liderada por Bismarck, su posición respecto al Estado y al de pertenencia a una nación, hacen que Nietzsche se aleje de Wagner hasta llegar a la completa ruptura de su amistad con el gran compositor alemán.

Otto Bismarck (llamado por el pueblo como "El Canciller de Hierro") buscó la integración de los principados y ducados del antiguo Sacro Imperio RomanoGermánico al reino de Prusia. Para alcanzar ese objetivo primero buscó la integración económica, mediante la construcción de un sistema de transporte ferroviario y el establecimiento de industrias y de un sistema monetario común, además de la instauración de un mismo régimen de escolaridad, que expandió la educación pública prusiana a esos pequeños estados de lengua germánica. Así se iría formando una conciencia nacionalista pangermánica en todos ellos alrededor de Prusia, a más de dar una educación técnica básica para for- mar la fuerza de trabajo necesaria para impulsar la revolución industrial que se había originado en Europa desde Inglaterra, lo que le permitió a este último país expandir el gran imperio colonial británico en prácticamente todos los otros continentes del mundo, por la presencia de su armada que era la más poderosa de la Tierra. El filósofo Johann Fichte después del desastre que implicó para Prusia su derrota militar por los ejércitos napoleónicos en la batalla de Jena en 1806, planteó al rey prusiano la imperiosa necesidad de establecer un sistema educativo público que forme y fortalezca la conciencia nacional y eleve la cultura técnica de la población al nivel necesario para desarrollar la industria prusiana. Este sistema de escolaridad tenía una organización de carácter militar, además de introducir a él la estructura de la industria moderna. Había que formar un producto humano como si fuesen mercancías e insumos para el desarrollo económico-industrial del país. Esta propuesta fue tomada por el rey (quien ejercía la monarquía absoluta, pero con la formación filosófica del pensamiento racionalista de los intelectuales de Europa, por lo que era parte del conjunto de reyes absolutos a lo que la historia los ha llamado Déspotas ilustrados) y la aplicó primero en Prusia, lo que permitió el desarrollo exponencial de la economía por medio de un sistema sostenido del desarrollo industrial más moderno de su época. El sistema de educación pública prusiano adquirió un gran prestigio mundial y muchos países del mundo que necesitaban el desarrollo de la escolaridad pública, como por ejemplo USA, enviaron misiones cuyo propósito era el de empaparse, y de primera mano, del sistema prusiano de educación.

La integración de un Estado nacional en el que exista una sola moneda, además 
de la libertad de transportarse libremente en su interior, lo que implicaba un bajo costo de transporte y la libertad de comercialización de las mercancías acabó con el sistema feudal en Europa. Ya no era necesario pagar a los propietarios de las tierras un impuesto para obtener el derecho de transportarlas en su interior. Además, significó la unidad del sistema jurídicopolítico en el aparato del Estado, cosa que había introducido Napoleón inspirándose en el sistema jurídico del antiguo Imperio romano. La unidad y conciencia de la lengua y costumbres comunes a toda la población se transformaron en las bases del Estado-nación impulsado por la burguesía nacional.

Todo este proceso origina el movimiento cultural del Romanticismo alemán, mediante el cual se rescatará los mitos, cuentos y leyendas de los pueblos germánicos, y se procederá a la constitución de la gramática de la lengua alemana. Toda esta transformación fue impulsada por Otto Bismarck y se la llamó el Zollverein alemán.

Como producto de la derrota de Napoleón en Waterloo, Francia había perdido la Lorena y Alsacia. Cuando Napoleón III sube al trono como emperador de Francia se propuso realizar la acumulación de fuerzas bélicas y el fortalecimiento del ejército francés. Una vez que sus asesores le indicaron que Francia estaba en condiciones de replicar lo que hizo su tío Napoleón I, entonces el nuevo emperador francés declaró la guerra a Prusia. Como resultado del Zollverein, todos los principados y ducados germánicos se sumaron a las fuerzas del ejército prusiano liderado por Bismarck. El desenlace fue una desastrosa derrota del ejército francés. Cuando en París se conoce el resultado de la guerra, emerge una fuerza política nueva, la de la clase obrera la que se insurrecciona contra Napoleón III y pasan a formar un gobierno proletario al que se le denominó "La Comuna de París" que sería el primer intento de establecer un Estado Socialista en la historia. En esas circunstancias Bismarck y Napoleón III unifican su fuerza militar para aplastar a la Comuna, lo que así hicieron en el periodo de una semana. Entonces Bismarck y delegados que representaban a Francia, firmaron el acuerdo de paz en el Palacio de Versalles. Luego Bismarck se reunió con sus aliados de los ducados y principados germánicos en el Salón de los Espejos donde declararon todos en unirse en el Imperio alemán, el segundo Reich después de Carlomagno.

La sociedad feudal se había derrumbado. La influencia todopoderosa de la religión cristiana se había puesto en entre dicho, y muchos de los dogmas cristianos habían sido cuestionados por Kant y Hegel. Hegel fue el primero en afirmar que el Dios de la representación religiosa había muerto, y que a Dios se lo puede hallar en el proceso del desarrollo de la historia humana, afirmación hecha en su obra El Concepto de Religión.

Nietzsche igual que Marx pretende construir una visión materialista de la historia. Marx la encuentra en la lucha de clases sociales y su relación con el desarrollo de las fuerzas productivas. Nietzsche lo hace retomando la tesis de Hegel, afirmando la muerte de Dios. Antes el hombre carecía de libertad por la figura de autoridad de Dios y sus normas religiosas. Muerto Dios el hombre era completamente libre de construir sus propios valores que le permitan nuevamente volver a ser un ser terrenal, dado que los trasmundos no existen. Así, el hombre puede enfrentar su condición de ser el puente entre el animal 
y el superhombre. Nietzsche también denuncia a Platón y a los post-socráticos el dar el paso hacia el encadenamiento más feroz que haya sufrido la humanidad, el cual es plantear la existencia de un solo Dios. Prefiere la alternativa pre-socrática, lúdica y a la vez heroica del paganismo de Dionisos. Esta perspectiva es recogida por el filósofo Heidegger al afirmar que como el hombre está atrapado en el tiempo para él es imposible llegar al Ser, al Ein Sof. Solo le quedaría la alternativa de llevar una vida heroica, la que sería su dasein. Heidegger introduce a Nietzsche en la Academia germánica en su condición de Rector de la Universidad de Viena, puesto al que lo habían ascendido los nazis por apoyar el proyecto pangermánico de unificar a todos los alemanes, incluso a los de Austria para formar el tercer Reich.

Nietzsche plantea cuatro puntos fundamentales en su sistema filosófico: la muerte de Dios, la libertad del hombre de construir sus propios valores al integrarlo nuevamente a la Tierra como un puente entre el animal y el superhombre, el advenimiento del superhombre y la tesis del Eterno Retorno de lo Mismo. Para alcanzar la condición de superhombre, se debe dejar a un lado la compasión, la que nos alejó de nuestra condición terrenal y porque la compasión había sido la causa de la muerte de Dios. Además, hay que tomar distancia de todos los sistemas que no sean aristocráticos como la democracia y el socialismo, dado que eran los medios por los cuales los hombres inferiores, revestidos de su fuerza oculta en la masa, quieren hacerse del poder de forma ilegítima y contra natura. El poder es exclusivo del aristócrata, quien no requiere del Estado para el ejercicio de su individualidad, y solo él es quien tiene la potestad de la verdad. Mira al Estado con la misma repugnancia con la que mira a los hombres inferiores sumidos en la masa.

Al contrario de los post-socráticos como Platón y Aristóteles que argumentaban siguiendo un discurso lógico, mediante el método de planteamiento del problema, el análisis de la legitimidad del problema, el manejo argumentativo usando la lógica y los conceptos fundamentales así como los conocimientos previamente demostrados como verdaderos en el contexto en que tiene lugar el problema, Nietzsche renuncia al recurso argumentativo y lógico. Así que plantea sus ideas a martillazos. Son metáforas de enorme carga psicológica que se afirman sin más. A lo sumo recurre a la analogía y a la narrativa como alternativa literaria. Esto se ve en su obra Así hablaba Zaratustra, que no se sabe si clasificarla entre la narrativa poética o en el pensamiento filosófico.

En su primera etapa su preocupación tiene que ver con su perspectiva dionisiaca de la vida que expone en su primera obra El nacimiento de la tragedia en el espíritu de la música. Luego, publicó también Para una filología del futuro, que fue duramente criticado por Ulrich von WilamowitzMoellendorff, lo que le hizo más notorio en los círculos filológicos, pero que le costó no ganar una cátedra en la Universidad de Basilea. Posteriormente, publicó una obra llamada Consideraciones intempestivas, que eran cuatro ensayos que criticaban a la actualidad cultural alemana, que la consideraba completamente falsa y equivocada.

Su estabilidad psicológica es un tema no muy bien aclarado. Primero desprecia al Zollverein prusiano, y mira a Bismarck con la desconfianza con que un pueblerino mira a un extranjero, por lo que adopta la ciudadanía suiza. Sin embargo, en 1870 se 
pone de parte de la causa prusiana en su guerra contra Francia, pero dada la neutralidad de Suiza, esta acepta que Nietzsche participe solamente como camillero. Su paso por la milicia fue tan solo por un mes. Además de ser testigo del carácter traumático de la batalla se enfermó con difteria y disentería, las que marcaron su mala salud por el resto de su vida. Es posible que antes de 1870, por su disipada vida, haya contraído en algún burdel sífilis, la que atacará a su sistema nervioso, llevándolo primero a la locura y luego a su temprana muerte. Existe una corriente de estudiosos que consideran que la obra de Nietzsche solo fue posible por un pensador insano y loco, quienes encuentran ya rastros de su alienación cuando escribió las Consideraciones intempestivas que las redactó separadamente entre 1873 y 1876 . En este periodo el círculo social de Nietzsche se amplía cuando el pensador hace amistad con Malwida von Meysenbug, Hans von Bulow y Paul Rée. Este último es quien después de 1876 influenció en la atenuación del pesimismo de los primeros escritos de Nietzsche. Pero dada la evolución del nacionalismo de Wagner del cual Nietszche se decepcionó profundamente, fue más clara su alienación de mundo.

Este proceso se puede ver cuando en 1878 publica Humano, demasiado humano, que es un libro de aforismos que cubren un gran espectro que van de la metafísica hasta la moralidad y de la religión al sexo. En esa obra establece la ruptura definitiva con Wagner y la filosofía de Schopenhauer y el establecimiento de distancias con Deussen y Rohde.

En 1879 su salud empeora, y fue forzado a abandonar su puesto como profesor. Debido a su salud es obligado a buscar climas más temperados haciendo que Nietzsche viaje continuamente estable- ciéndose provisionalmente en las ciudades italianas de Génova, Rapallo y Turín, así como la ciudad francesa de Niza. A veces regresaba a Naumburgo a visitar a su familia. Es notable la relación que tenía con su hermana, la misma que adolecía de características endogámicas.

A partir de 1878 Nietzsche publica un libro por año hasta 1888. En 1881 Nietzsche publica Aurora. Reflexiones sobre principios morales, en 1882 la primera parte de La Gaya Ciencia. En ese año conoció a Lou Andreas-Salomé, una joven intelectual judía que siempre miró a Nietzsche como "El maestro". Nietzsche se enamoró de ella y participó en un triángulo formado por Rée (de origen judío), Salomé y Friedrich Nietzsche. Cuando Nietzsche le propone matrimonio a Lou Salomé ella no lo aceptó. Sin embargo, continuó en una relación epistolar con ella. Lou Salomé de vez en cuando mantenía correspondencia con Freud, introduciéndolo al pensamiento de Nietzsche. Incapaz de soportar las presiones de su hermana y de su madre, se marchó a Rapallo, en donde en diez días, después de 18 meses de incubación, escribió la primera parte de Así habló Zaratustra.

Ahora, bajo la impronta personalísima del Zaratustra sobre sus obras posteriores, su escritura resultó más "intempestiva" y se la leyó (poco) solo en la medida en que pareciera adecuarse a las convenciones morales e intelectuales del momento. Abandonó su plan de convertirse en un poeta público y reconocido. Sus libros eran tan buenos como poco vendidos. En 1885 editó únicamente 40 copias de la cuarta parte de Así habló Zaratustra, y solo una pequeña parte fue distribuida entre sus amigos más allegados. En 1886 escribió Más allá del bien y del mal. Con este libro 
y con la aparición entre 1886 y 1887 de sus segundas impresiones de trabajos tempranos (El nacimiento de la tragedia; Humano, demasiado humano; y, La Gaya ciencia), vio completado su trabajo y se esperanzó que una oleada de lectores apreciara sus artículos. De hecho, el interés en Nietzsche aumentó en esa época, aunque esto fue apenas percibido por él.

En 1886, su hermana Elisabeth se casó con el antisemita Bernard Forster y viajó con él al Paraguay para fundar una colonia alemana, un plan al que Nietzsche contestó con ironía.

Nietzsche comenzó a tener ataques frecuentes, lo que le imposibilitó realizar un trabajo continuo. En 1887, Nietzsche escribió rápidamente su polémica Genealogía de la moral. Intercambiaba correspondencia con Georges Brandes, quien al comienzo de 1888 desarrolló en Copenhague la primera lectura pública de la obra filosófica de Nietzsche y su estudio.

En el mismo año Nietzsche escribió cinco libros basados en sus voluminosas notas, fruto de un largo trabajo continuo, que en un principio pensaba reunir bajo el título de La voluntad de poder. Su salud pareció mejorar y aquel verano estuvo de buen humor. Pero hacia fines de 1888 , sus escritos y cartas empezaron a revelar una sobreestimación patológica de su estatus y su destino. Sobrevaloraba la respuesta creciente de sus artículos, sobre todo por la reciente polémica al caso de Wagner. En su cumpleaños 44, Nietzsche tuvo un colapso mental. Fue detenido por haber generado algún tipo de desorden público por las calles de Turín. En los días siguientes, escribió breves cartas a sus amigos, incluida Cósima Wagner y Jacob Burckhardt, en los que mostraba signos de demencia y megalomanía.

Fue internado en el hospital psiquiátrico en una clínica de Basilea. Más tarde su madre decidió llevarlo a una clínica de Gena. Durante este proceso, Overbeck y Gast contemplaban la idea de qué hacer con el trabajo no publicado de Nietzsche. En enero de 1889 se pusieron a planear la salida del "Crepúsculo de los ídolos", por esa época ya impreso y atado. En febrero ordenaron una edición privada de 50 copias de Nietzsche contra Wagner, pero el publicista C. G. Nauman en secreto imprimió 100. Overbeck y Gast decidieron publicar El Anticristo y Ecce homo a pesar de su contenido más radical. La hermana de Nietzsche tuvo que regresar del Paraguay después del suicidio de su esposo, luego de lo cual ella leyó y estudió los trabajos de Nietzsche, y pieza por pieza tomó control sobre ellos y su publicación. Después de la muerte de Franziska (madre de Nietzsche) en 1897, Nietzsche volvió a Weimar, donde fue cuidado por Elisabeth hasta la muerte de su hermano el 25 de agosto de 1900.

\section{La esencia del pensamiento de Nietzsche}

Inicialmente Nietzsche sigue los estudios de teología para ser un pastor cristiano como lo fue su padre. Pero su padre y hermano menor mueren por enfermedades infecciosas, y ese hecho le demuestra la impotencia de la oración. Además, la evolución de la filosofía había descartado la comunicación con Dios que para Kant está en la incognoscibilidad del Ser en Sí y para Sí, y la afirmación de Hegel de la muerte del Dios de la representación ("El concepto de religión") y su descubrimiento en el despliegue de lo absoluto para transformar el Ser en Sí en el Ser para Sí, 
mediante la manifestación de lo absoluto en la presencia de la historia. Así, Dios deja de ser el Ser a quien acudimos en nuestras oraciones por medio de una relación personal, y pasa a ser según Hegel un Principio Absoluto que da esencia a las cosas, siendo la "cosa en sí Kantiana" inalcanzable para la razón humana, como el Absoluto Hegeliano que solo se manifiesta en el proceso evolutivo de la historia. Eso implica poner en entredicho el papel del individuo como el realizador de la historia.

Las ciencias positivas como la Física, la Química y la Biología analizan el objeto de su estudio buscando relaciones de causalidad de carácter material, y ya se habían independizado de conceptualizaciones míticas como la astrología y la alquimia, que tenían una gran carga simbólica de quienes somos los seres humanos en relación con el Todo. El racionalismo científico producto de la síntesis del empirismo introducido por Bacon con la racionalidad establecida por Descartes y desarrollada por el denominado "racionalismo continental" naturalmente desembocan en Kant y la Crítica de la razón pura, mediante la cual se defiende, desde la razón, la física de Newton, y con la Crítica de la razón práctica que tiene que ver con el plano de la ética y de la estética. Le suceden una serie de filósofos racionalistas hasta llegar a Hegel, quien encuentra que en todo proceso natural o social participan pares de opuestos que se diferencian en la cantidad y que tienen la misma naturaleza. Si entre los opuestos surge una síntesis, inmediatamente surge una antítesis. Este proceso permite la transformación del Ser en sí hasta llegar al Ser para sí. Todo esto se ha dado en el marco de la historia, en la que "lo absoluto" se va manifestando, hasta llegar a la síntesis entre la forma (el Dios de la representación) con su contenido (EI espíritu absoluto). Según Hegel esto explica el carácter del Estado, pues por su intermedio se manifiesta tal síntesis. Esta idea agradó a los déspotas ilustrados de Europa que estaban listos a hacer cambios fundamentales en la sociedad gracias al poder del Estado que los reyes encarnan.

La vida de Nietzsche desde su niñez fue de sometimiento a un conjunto de creencias religiosas en las que el ser humano es un ser indigno ante Dios por nacer en la condición del pecado original, y quizá lo suficientemente indigno como para no escuchar sus oraciones cuando su padre enfermó gravemente, y desde allí se encuentra con la muerte. Un año más tarde sucede lo mismo con su hermano menor, quien también fallece. $Y$ más tarde en su juventud, cuando estudia teología y filosofía para llegar a ser un pastor como su padre, compara las distintas escuelas filosóficas que se construían usando argumentos racionales, con el conjunto de creencias que debía tener y aceptar como dogmas del cristianismo, a los que no hay que probar nada sino simplemente aceptarlos como un acto de fe, el acto de una creencia irracional. Las mismas escrituras estaban en conflicto con los últimos descubrimientos de que la edad de la Tierra es muchísimo más antigua que lo que enseñaba el Génesis. Además, Darwin había escrito un libro to suficientemente documentado desde sus observaciones de especies de plantas y animales, que se habían formado por pequeños cambios biológicos para adaptarse al medio ambiente, y que por efecto acumulativo originaban nuevas especies en millones de años. Copérnico había desplazado a la Tierra como centro del sistema solar y la había colocado como un planeta más que gira alrededor del Sol en una órbita circular. ¿Cómo pudo Josue detener en el cielo al Sol para que el día 
sea más largo y así el ejército de Israel tenga el tiempo suficiente para destruir a todos sus enemigos en una batalla? Vemos que en la naturaleza los animales que se hallan en la cima de la cadena alimenticia son los más fuertes y agresivos. ¿Cómo es que Jesús enseñaba el mostrar la segunda mejilla si te golpeaban en la primera, si esa enseñanza estaba en franca contradicción con lo que se ha visto en la naturaleza y en la propia historia humana? ¿Roma no llegó a formar su imperio ejerciendo la violencia e incluso desapareciendo a pueblos y culturas enteras? ¿Acaso no hicieron lo mismo los españoles con los indígenas de sus colonias de América? ¿Y los anglosajones con los indígenas de Norte América? Y todo esto los europeos lo habían hecho en el nombre de Jesús y del Dios de los judíos. Nietzsche concluye que toda la crisis de valores de occidente radica en el hecho que la civilización occidental había actuado en contra de los principios del cristianismo, y por lo tanto esa civilización había asesinado a Dios. La compasión no la encontramos en la naturaleza. Un león se come a una gacela luego de haberla perseguido, alcanzado y asesinado sin compasión. En el tiempo que le tocó vivir a Nietzsche, ¿̇acaso sus abuelos no conocieron a Napoleón quien había aniquilado a los ejércitos prusianos?, ¿la famosa Revolución Francesa con sus principios de Igualdad, de Libertad y de Fraternidad acaso no había bañado en sangre el territorio francés? ¿Y quiénes son los que escriben la historia?, ¿acaso no son exclusivamente los vencedores?

Se dio cuenta así que el Dios cristiano había muerto. Lo había matado su compasión por los hombres, porque estos nunca actuaron con compasión.

\section{Comentarios}

COMENTARIO 1. Veamos las cosas desde un punto de vista de la paleontología actual. El homo sapiens que se originó en Sud África hace 150.000 años, pudo emigrar hacia el norte porque el enorme desierto del Sahara que se extendía mucho más hacia el sur que ahora, por eventuales cambios climáticos se transformó en una estepa hace unos 100.000 años. Algunos emigraron a oriente pasando por las tierras de Canaán, y otros viajaron a España y llegaron hasta lo que hoy es Francia. La paleontología los denomina el hombre de Cromañón. Cuando llegaron a valles fértiles de abundante caza en lo que hoy es Francia, se toparon con otra especie humana, los hombres de Neandertal. El hombre de Cromañón era físicamente más débil y frágil que el de Neandertal. Si un hombre de Neandertal hubiese encontrado a un hombre de Cromañón solitario, bebiendo agua del río, y lo hubiera atacado, con seguridad el hombre de Cromañón no hubiese salido vivo del mal encuentro. Sin embargo, los hombres de Cromañón parece que nunca caminaban solos sino en patruIla. Si alguno de ellos hubiese sido lastimado estaban los otros del grupo para auxiliarlo. La edad del hielo obligaba al hombre de Neandertal a vivir en grupos pequeños para que no les falte el alimento. Si dos grupos neandertales se encontraban guerreaban entre ellos hasta la muerte, porque tener prisioneros es tener más bocas que alimentar. Así que carecían de la empatía suficiente para poder agruparse en tribus más grandes. Eso no sucedía con el hombre de Cromañón. Desarrollaron la suficiente empatía para vivir en grupos más grandes y hasta en tribus numerosas. Su nivel de colaboración entre los individuos era mucho más estrecha que la que podían establecer los neandertales entre sí. 
Nuestros antepasados eran mucho más solidarios, amorosos y compasivos con los más débiles. Los ancianos eran respetados por su experiencia para construir armas de caza, tácticas de rastreo de las presas, conocimiento de hiervas medicinales. Eran los sabios del grupo y por lo tanto respetados. Su organización social y desarrollo del lenguaje les permitía distribuirse mejor las tareas en el grupo. Sus armas eran más sofisticadas que las de los neandertales, pues eran elaboradas con mejores técnicas, y es muy probable que hayan usado el arco y flechas con puntas envenenadas. La compasión del grupo por protegerse unos a otros hizo la diferencia con el hombre de Neandertal, el cual se vio forzado a emigrar más hacia el norte donde los alimentos escaseaban hasta cuando se extinguieron. La solidaridad y la compasión humanas marcaron la diferencia entre vivir o extinguirnos.

Es cierto que las tribus del hombre de Cromañón también competían entre sí por controlar espacios geográficos ricos en caza y en alimentos de recolección. Pero el punto está en que tribus distintas podían aliarse y colaborar cuando su existencia individual entraba en peligro, lo que era impensable para los neandertales. Aún, hoy, cuando se produce un terremoto o un tsunami los sobrevivientes actúan instintivamente para salvar a las víctimas heridas o rescatar a los cuerpos de los fallecidos. Gracias al hecho de que el homo sapiens instintivamente sea solidario, sumándose a eso nuestra capacidad de razonar para discernir entre causas y efectos en la naturaleza, la especie humana se halla ahora en la parte superior de la cadena alimenticia.

Así, cuando Nietzsche en su filosofía pone al individuo sobre la tribu, y más aún cuando exige que tal individuo no debe guardar ninguna compasión en su corazón para llegar a la condición de superhombre, de hecho está en conflicto con la condición humana. Los grandes avances de la humanidad han sido formulados por personas que han albergado un gran amor por la misma, como ha sido el caso de Confucio, Lao Tse, fundador de Taoísmo, de Pitágoras y la ética de su escuela y de Siddhartha Gautama llamado también el Buda o el Iluminado, los cuales vivieron alrededor del 600 a.C. Esta curiosa coincidencia del aparecimiento de líderes espirituales en el mismo periodo y en sitios tan diversos, Carl Gustav Jung la denomina sincronicidades. Sin la figura de Jesús y sus enseñanzas sería impensable el desarrollo de la civilización occidental hasta el nivel que llegó en la época en que vivió Nietzsche, en la que la ciencia, luego de la mecánica de Newton, había llegado a formular el electromagnetismo y concluir la termodinámica. En el campo de las matemáticas, ya se había desarrollado significativamente la geometría analítica, se habían iniciado además la formulación del cálculo en términos estrictamente lógicos, la formulación fundamental de las geometrías no euclidianas (Lobachevsky, Riemann), se habían realizado progresos significativos relacionados con el cálculo vectorial, series de Fourier, ondas no-lineales, análisis tensorial, etc.

COMENTARIO 2. Nietzsche odia a la burguesía por su arribismo económico y político, y de hecho se opone a ella criticando las tesis democráticas como la constitución de un Estado con división de poderes, y con autoridad sobre una nación unitaria. Esa fue la causa de su ruptura con Wagner que apoyaba la iniciativa pangermánica de Prusia. Para demostrar su repulsión a ese proyecto político adopta la ciudadanía suiza. Hombre de contradicciones que era, 
se suma al apoyo de Prusia en su guerra contra Francia y quiso alistarse para servir como soldado al ejército de Prusia, pero por adoptar la ciudadanía suiza, este país solo le permitió servir como camillero.

Sin embargo, él apoya la tesis individualista de la burguesía, cuando habla del superhombre, como un ser sin compasión aferrado a los bienes de la tierra y alejado de la creencia de supramundos puesto que estos no existen. Rigurosamente no ofrece una posición nítidamente materialista, como en el caso del marxismo y del anarquismo. Exige a su superhombre ser completamente dionisiaco, pegado a la tierra, disfrutando de las experiencias de sus sentidos. Así, Nietzsche retrocede al paganismo crítico presocrático. Niega absolutamente el mundo de las ideas de Platón en el que se hallaban los arquetipos, la geometría y las ideas supremas del Bien, la Belleza y la Justicia. Así, se enfrenta directamente con la ciencia y con la razón, puesto que afirma la irracionalidad de la realidad. Nietzsche rechaza la supuesta objetividad del conocimiento científico, la existencia de las leyes de la naturaleza, la racionalidad del mundo y el poder explicativo de las matemáticas.

Según Lou Andreas-Salomé, Nietzsche critica las siguientes creencias básicas que se incluyen en la práctica científica, o que parecen vinculadas con ella:

1. Su objetividad: con la expresión "conocimiento objetivo" nos referimos al que es capaz de describir el mundo independientemente de las peculiaridades o rasgos de la persona o grupo que lo alcanza. Un conocimiento es objetivo cuando no está influido por los intereses o por los rasgos del sujeto, cuando describe las cosas sin aña- dirles nada que no les pertenezca realmente. Filósofos como Platón, Aristóteles, Santo Tomás, Descartes y gran parte de lo mejor de la tradición filosófica creyeron que la filosofía podía alcanzar ese conocimiento perfecto, aséptico, imparcial, y con la aparición de la ciencia moderna muchos consideraron que se hacía real el afán por la verdad única y absoluta típico de todo el mundo occidental. Sin embargo, la posición de Nietzsche es radicalmente contraria a estas afirmaciones y conecta con otra línea filosófica completamente desacreditada: el relativismo, escepticismo y subjetivismo. Nietzsche defiende el perspectivismo, la tesis según la cual todo conocimiento se alcanza desde un punto de vista que es imposible prescindir: las características del sujeto que conoce (psicológicas, sociales, físicas, la peculiaridad personal, la misma biografía) hacen imposible superar la propia perspectiva; no podemos desprendernos de nuestra subjetividad cuando intentamos conocer la realidad; incluso la creencia en la objetividad es un punto de vista más, pero un punto de vista que esconde la relatividad de su origen, su dependencia de concepciones establecidas y no evaluadas o controladas.

Un punto de vista opuesto al de Nietzsche, basado en un discurso científico, rescata el carácter objetivo del mundo, liberando así a la Mecánica Cuántica de la perspectiva subjetivista tradicionalmente aceptada (ver [1] y [2] para más detalles).

2. La existencia de leyes naturales: en el mundo no existen leyes, las leyes que el científico cree descubrir son inven- 
ciones humanas; no existen regularidades en el mundo, no hay leyes de la naturaleza. Si entendemos por leyes de la naturaleza supuestos comportamientos regulares de las cosas, Nietzsche rechazará la existencia de dichos supuestos comportamientos regulares y necesarios: ¿Por qué las cosas iban a comportarse regularmente?, ¿̇en virtud de qué necesidad? Siguiendo un planteamiento ya conocido en la historia de la filosofía, el planteamiento de Hume, Nietzsche considera que las relaciones entre las cosas no son necesarias (para emplear un término clásico, son contingentes), son así pero perfectamente pueden ser de otro modo. Las cosas se comportarían siguiendo leyes o necesariamente si hubiese un ser que les obligue a ello (Dios), pero Dios no existe; las leyes y la supuesta necesidad de las cosas son invenciones de los científicos. Si creemos en las leyes naturales es porque nos interesa creerlo, no porque realmente existan; el orden en el mundo es una creencia infundada, nosotros creemos en ese orden para hacer más soportable la existencia, para sentirnos más cómodos ante el entorno hostil. "Las cosas no se comportan regularmente conforme a una regla; no hay cosas (se trata de una ficción), tampoco se comportan bajo necesidad. En este mundo no se desobedece; pues el ser algo tal cual es, de tal fuerza, de tal debilidad, no es el resultado de la obediencia, regla ni necesidad" (La Voluntad de Poder, [4]).

3. La validez del ejercicio de la razón: en este punto la crítica a la ciencia se incluye en la crítica más general de toda actitud (incluida la filosófica) que con- sidera a la razón como instrumento legítimo para el conocimiento. La razón no se puede justificar así misma: ¿Por qué creer en ella?; la razón es una dimensión de la vida humana, aparece de forma tardía en el mundo y muy probablemente, dice Nietzsche, desaparecerá del universo; y nada habría cambiado con dicha desaparición. Junto con la razón, en el hombre encontramos otras dimensiones básicas (la imaginación, la capacidad de apreciación estética, los sentimientos, el instinto...) y todas ellas pueden mover nuestro juicio, todas ellas son capaces de motivar nuestras creencias. La razón no es mejor que otros medios para alcanzar un conocimiento de la realidad (en todo caso es peor pues el mundo no es racional). La ciencia se equivoca al destacar exageradamente la importancia de la razón como instrumento para comprender la realidad.

4. Legitimidad de las matemáticas: la matemática es una ciencia adecuada para expresar con bastante aproximación el comportamiento de las cosas. Para Nietzsche, sin embargo, esta forma de entender el mundo es aún más errónea que otras formas de cientificidad. Las matemáticas puras no describen nada real, son invenciones humanas; en el mundo no existen líneas rectas, ni triángulos, ni ninguna de las perfectas figuras a las que se refiere la geometría. En el mundo no existen números ni siquiera propiamente unidades. Cuando decimos que algo es una cosa (una mesa, un árbol,...), lo que hacemos es simplificar la realidad que se nos ofrece a los sentidos, someterla a un concepto, esconder su pluralidad y variación cons- 
tante. Las matemáticas prescinden de la dimensión cualitativa del mundo, de su riqueza y pluralidad. Podemos entender la valorización que Nietzsche hace de la matemática comparándola con la platónica: para Platón el matemático descubre entidades reales y objetivas que están más allá del mundo físico, en el Mundo Absoluto de las Ideas; Nietzsche considera, sin embargo, que no existen tales entidades, ni realizándose en el mundo físico ni, mucho menos, en un mundo independiente y eterno. Para Platón, Pitágoras descubre el teorema que lleva su nombre, para Nietzsche, lo inventa.

En cuanto al origen de la ciencia, Nietzsche señala dos motivos:

a) Su utilidad: la ciencia nos permite un mayor control de la realidad, la previsión y dominio del mundo natural; pero, recuerda frecuentemente, la eficacia no es necesariamente un signo de verdad.

b) Es consecuencia de un sentimiento decadente: ocultar un aspecto de la naturaleza que solo los espíritus fuertes consiguen aceptar. El caos originario del mundo, la dimensión dionisiaca de la existencia. La ciencia nos instala cómodamente en el mundo previsible, ordenado, racional.

Esta perspectiva de Nietzsche, mencionada en el ítem b), se contrapone con la tendencia científica actual, donde a partir de sistemas con un alto componente caótico se pretende encontrar formulaciones $y$ leyes que describan dichos sistemas de una manera racional. En [1], los autores consideran la existencia de un campo de acción de fondo "caótico" para presentar una interpretación objetiva de la Mecánica Cuántica.

COMENTARIO 3. Nietzsche plantea la tesis del eterno retorno de lo mismo. Consecuentemente con la cosmovisión pagana presocrática, Nietzsche vuelve a la concepción cíclica del tiempo, la que es propia de las civilizaciones agrícolas antiguas. Para ellas era de vida o muerte saber las regularidades de las estaciones y su relación con el patrón astronómico cíclico del cielo. Sus referentes eran la aparente posición del Sol en el horizonte, las fases de la Luna y la posición de la estrella de la mañana y la del atardecer. La medición del tiempo, usando el cielo, determinaba la época de la siembra y de la cosecha. Como este filósofo descarta a la razón, retorna al mito de que todo lo que fue es y será. En el Eclesiastés de la Biblia, Salomón afirma que no hay nada nuevo bajo el sol, que todo es cíclico y volverá a suceder.

Al negar la validez de la ciencia, descarta de un plumazo la revolución del pensamiento que implicó la tesis copernicana que dio lugar a las ideas de Galileo, Kepler hasta llegar a Newton. Es así que Newton introduce al tiempo como un devenir lineal común a todos los puntos del espacio vacío (espacio-tiempo absolutos), es decir introduce en la filosofía natural la concepción espacio-temporal del judeo-cristianismo, donde el mundo tuvo un origen y llegará a tener un fin cuando descienda del cielo la Jerusalén celestial con la que concluye la apocalipsis de Juan, con la que finaliza la Biblia.

Nietzsche como dionisiaco tenía que desechar esa concepción del tiempo. Para él, el universo nunca tuvo un origen ni tendrá un fin, simplemente es eterno. Así que dentro de esa eternidad no sería contra 
natura que todo se volviese a repetir si esperamos el tiempo suficiente. Sin embargo, la posición de la Cosmología actual se opone a la cosmovisión de Nietzsche. Justamente, usando la teoría de la relatividad general se demuestra que el universo se originó en el big-bang. Además, a comienzos del siglo XXI, por las observaciones del observatorio espacial Hubble, se ha determinado que las galaxias se están alejando unas de otras entre sí aceleradamente, de modo que el universo sufrirá una muerte térmica. Así, la idea de un universo eterno experimentalmente ha sido desechada. También, desde la segunda ley de la termodinámica, que afirma que en todo proceso se incrementa la entropía, la concepción de un universo cíclico resulta imposible.

COMENTARIO 4. La tesis de la voluntad de poder como característica del superhombre, no está lo suficientemente explicada, porque el mismo Nietzsche afirma que toda forma de vida tiene la voluntad de poder para afirmar su propia existencia y buscar mecanismos para que la especie permanezca en el tiempo. No hay que olvidar que en los 3.800 millones de años de la vida en la Tierra, el $99.98 \%$ de las especies se han extinguido. Los últimos descubrimientos de la paleontología han aclarado que los pájaros son dinosaurios evolucionados. Aquí y hoy sabemos que todos los dinosaurios se extinguieron hace 65 millones de años por el impacto de la Tierra con un asteroide un poco más grande que el monte Everest que cayó sobre el Golfo de México. Sobrevivieron los dinosaurios que se estaban transformando en pájaros por la ley de la evolución por selección natural.

La voluntad del poder de la vida es realmente sorprendente, pues la encontramos en sitios que hace 30 años se consideraban que eran incapaces de albergar vida, como lo son las chimeneas volcánicas en el fondo del mar. Así que si se llega a formar vida en alguna parte ella tiene la voluntad de poder para adaptarse a cualquier condición del medio ambiente por extrema que sea. A esas formas de vida se les conoce científicamente como extremófilos.

Así, retomando la idea de Darwin, todos los seres vivientes de nuestro planeta estamos emparentados. La prueba de esto es que todas las formas de vida tienen las moléculas de adenina, guanina, timina, citosina y uracilo en su código genético del ADN. Plantas y animales nos derivamos de la evolución por selección natural de un solo micro organismo inicial.

Nietzsche quizá comprendió que el hombre civilizado de su tiempo estaba completamente alejado de la voluntad de poder que conlleva la vida. Si llegamos a apreciar nuestra naturaleza animal es posible que reencontremos la voluntad de poder de la vida.

COMENTARIO 5. El lector se preguntará la razón de la realización de este ensayo sobre la filosofía de Nietzsche. Obedece a la necesidad de dar una posible respuesta a la paradoja a la que se ven sometidos los individuos al considerar por un lado su individualidad y por otro su masificación al interior de la sociedad. Nietzsche inicia un proceso en el campo de la filosofía de la negación de la racionalidad, que va desde Heidegger y concluye con el Existencialismo. Esto ha motivado el reaparecimiento de un pensamiento mítico y mágico que está creciendo de forma acelerada a través de los movimientos de "La nueva era" y la sobrevaloración de "La sabiduría ancestral". Algunos de los seguidores de estas concepciones místicas han usado la Mecánica Cuántica en su interpretación subjeti- 
va, según la cual el observador crea la realidad.

Frente a la situación antes expuesta, en [1] se rescata el concepto de la objetividad del universo físico como un aparato clásico de medida. Así, los autores consideran la presencia de un campo estocástico de acción de fondo el cual afecta a todas las partículas del universo, determinando de esta forma su existencia y su individualidad. La partícula elemental pasa por lo tanto a ser una manifestación singular de la totalidad del universo, mientras que Nietzsche coincide con la concepción newtoniana en la que es posible la existencia de objetos físicos sin relación con el todo de tal manera que el principio de inercia tenga sentido. A partir de tres supuestos fundamentales se deduce en [1] la función de densidad de distribución de la acción del campo de fondo del universo sobre la partícula elemental, la cual viene dada por:

$$
\phi(S)=\frac{1}{\sqrt{2 \pi} \sigma} e^{-\frac{S^{2}}{2 \sigma^{2}}}
$$

donde $\mathrm{S}=\mathrm{Px}-\mathrm{Et}, \mathrm{P}$ corresponde al momentum de la partícula, $\mathrm{E}$ denota su energía, $\mathrm{x}$ la posición, $\mathrm{t}$ el tiempo y $\sigma$ la desviación estándar del campo de acción de fondo. Además, se demuestra que $\sigma$ es "esencialmente" (proporcional a) $\hbar$, donde $\hbar$ es la constante de Planck $h=6.62606896$ (33) $x$ $10^{-34} \mathrm{~J} \cdot \mathrm{s}$ dividida para $2 \pi$. Aplicando la concepción filosófica individualista al estudio de una partícula elemental, se podría abstraer la influencia del resto del Universo sobre dicha partícula, por lo que de acuerdo a lo expuesto en [1] la fluctuación del campo de acción de fondo sobre la partícula sería cero (ya que no existiría un campo de acción de fondo del Universo) y usando los resultados encontrados en [1] la constante de Planck tendría que ser cero. Este último enunciado está en contradicción con el principio de incertidumbre de la Mecánica Cuántica, por lo tanto el individualismo de Nietzsche está en contraposición con la posición holística expuesta en [1]. También se deduce en [1] la ecuación de Schrödinger no relativista,

$$
\begin{aligned}
i \hbar \frac{\partial \psi}{\partial t}(\vec{r}, t)= & -\frac{\hbar^{2}}{2 m} \nabla^{2} \psi(\vec{r}, t) \\
& +U(\vec{r}) \psi(\vec{r}, t),
\end{aligned}
$$

donde $\psi(\vec{r}, t)$ es la representación espacio-temporal de la función de onda de la partícula, $\nabla^{2}$ es el operador Laplaciano tridimensional y $U(\vec{r})$ es la energía potencial de la partícula. Además, usando la teoría formulada en [1], se deduce en dicho trabajo el principio de incertidumbre de Heisenberg,

$$
\Delta x \Delta P \geq \sigma .
$$

Vale mencionar que como consecuencia del trabajo presentado en [1], se obtiene que el producto de las incertidumbres en la posición y en el momentum de la partícula están relacionadas con las fluctuaciones del campo de acción de fondo del Universo sobre la partícula, impidiendo aislar a la misma de la influencia de la totalidad. Así, a partir de estos resultados obtenidos por los autores se puede además deducir características intrínsecas de las partículas elementales (bosones y fermiones) como son su masa en reposo y su momentum angular intrínseco; estas últimas propiedades serán publicadas en futuros trabajos de los autores.

Finalmente, ya que Nietzsche no acepta la existencia de las leyes de la naturaleza (ver [3]), y niega la racionalidad inherente en ella, su posición está en contradicción con el espíritu científico. 


\section{BIBLIOGRAFÍA}

[1] ÁLVAREZ-SAMANIEGO, W.P., ÁlVAREZSAMANIEGO B. y MOYA-ÁLVAREZ, D. (2012). Una interpretación física de la constante de Planck (diciembre) Preprint (\texttt\{http://arxiv.org/abs/1306.0894\}).

[2] MOYA-ÁlVAREZ, D. (1994). El campo de acción. Una nueva interpretación de la Mecánica Cuántica, editado por la Escuela Politécnica Nacional, Quito, Ecuador.

[3] NIETZSCHE, F. (1985). Obras inmortales, Tomo 1, Barcelona, España, Edicomunicación S.A.

[4] NIETZSCHE, F. (1985). Obras inmortales, Tomo 3, Barcelona, España, Edicomunicación S.A. 